\title{
THE DEVELOPMENT OF THE AXIAL VEINS AND LYMPHATICS IN TRAGULUS MEMINNA, ERXLEBEN
}

FREDERICK TILNEY

From the Anatomical Laboralory, Columbia University

FOURTEEN FIGURES ${ }^{1}$

MATERIAL

The material on which this investigation is based consists of five embryos of the ruminant ungulate, Tragulus meminna (Indian Chevrotain) measuring $5 \mathrm{~mm}$., $6 \mathrm{~mm}$., $13 \mathrm{~mm}$., $20 \mathrm{~mm}$. and $23 \mathrm{~mm}$. respectively. These were obtained by exchange from the Smithsonian Institute through Dr. A. Hrdlicka. The series represents the entire embryological material of this form collected during a number of years in Borneo and adjacent islands of the Malay Archipelago by Dr. Abbott of the Institution.

In view of the very great importance of Tragulus to the phylogenetic interpretation of the marsupial and placental vascular system, and of the probability that further embryos of this animal will not soon again become available for study, it seems advisable to publish the main results of the investigation based on the material now in hand. This becomes all the more imperative since we possess the complete account of the development of the postcava in embryos of Didelphis marsupialis furnished by McClure ('03), and hence have the opportunity of directly comparing the available series of Tragulus with the corresponding marsupial stages.

The two smaller $(5 \mathrm{~mm}$. and $6, \mathrm{~mm})$ and the two larger (20 $\mathrm{mm}$. and $23 \mathrm{~mm}$.) embryos of Tragulus here described proved to be admirably fixed and preserved and well adapted for minute and detailed study. The intermediate embryo of $13 \mathrm{~mm}$. is in a less satisfactory condition and has hence only been used

${ }^{1}$ Expense of illustrations borne by author. 
to bridge the gaps between the earlier and the later stages in certain regions, in which its preservation permitted definite conclusions.

In a single adult specimen of Tragulus, McClure ('06) found that the post-renal division of the post-cava was placed directly in front of the aorta and formed by the union of the common iliac veins, this union taking place ventral to the aorta. These relations correspond to one of the three types of post-cava described by him ('03) in Didelphis marsupialis and figured in his plate 2 as no. 8. MeClure concludes that this condition allies the venous organization of Tragulus more closely to that of the marsupials than to any of the known ruminants. In a verbal communication to the writer, Dr. McClure states that his earlier observations have been confirmed by the subsequent examination of three additional adult specimens of the animal.

Beddard ('07) observed the same relations of the aorta to the post-renal segment of the post-cava in three adult specimens of Tragulus. One male adult and three male fetuses in the Columbia collection show the post-renal segment of the post-cava directly in front of the aorta. The conditions in the adult specimen are illustrated in fig. 1 . In Tragulus the axial venous channel from the confluence of the internal and external iliac veins (fig. 1, 36 and 37) to the renal level consists of two parts; $a$, the common iliac veins (fig 1,38) (paired portion of the postcava, this latter term being used to keep the account in accord with McClure's description) and $b$, the unpaired portion of the post-cava, ventral to the aorta (fig. 1, 39). The unpaired portion is $6.5 \mathrm{~cm}$. in length and extends from the confluence of the common iliac veins to the renal anastomosis. The common iliacs are $4.9 \mathrm{~cm}$. in length and extend from the confluence of the internal and external iliac veins to the paired portion of the post-cava. Each common iliac vein receives the sex vein of the corresponding side (fig. 1, 40). Tragulus differs, in this respect, from the majority of marsupials in which the sex veins, as has already been shown by Schulte ('07) and Schulte and Tilney ('09), empty into the unpaired portion of the post-cava or into the post-cava and left renal vein. 
With reference to the development of the systemic lymphatics the material does not furnish conclusive evidence in all particulars. The organization of the lymph sac, however, is identical with that observed 'in the domestic cat by Huntington and McClure ('10). The younger embryos present all the characteristics of the primary venous stage, while the older specimens show the several details of structure typical of the late veno-lymphatic, pre-lymphatic and definite lymphatic stages. The systemic lymphatics, at first, are entirely independent of the lymph sacs and only secondarily acquire connections with them in completing the thoracic duct formation. In the specimens examined they showed no genetic relation to the veins, although their exact histogenesis could not be determined on account of the limited material.

The Born method of reconstruction was employed with a magnification of 100 diameters for purposes of topographical study and 200 diameters for obtaining regional detail. All measurements in the embryo were made from sections after fixation upon the slide and, in most cases, computed from figures obtained at a given magnification. None of the embryos was injected.

Venous organization of the $5 \mathrm{~mm}$. embryo (fig. 2)

This embryo presents an imperfectly closed neural tube in the entire spinal region. Its venous channels have a bilateral, symmetrical arrangement, there being four sets of paired trunks, all parallel with the long axis of the body. In addition to these drainage lines there are two plexuses, one, the perimescnephroic plexus surrounding the mesonephros, the other, the umbilicocardinal plexus which is still active in draining the territory of the body wall into the umbilical and post-cardinal veins.

1. The umbilical veins (fig. 2, 6). These are the largest channels present; they are as yet equal in size and show no tendency to lose their bilateral, symmetrical arrangement. No communication has been established with the hepatic sinusoids, so that the two umbilical veins are still independent vessels. They are, to a considerable extent, concerned in drainage of the body 
as well as in placental circulation. This is shown by the rich umbilico-cardinal plexus which permeates the lateral somatic wall. Each vein opens into the sinus venosus of its own side in common with the vitelline entrance and forward of the Cuvierian approach (fig. 2, 10).

2. The omphalomesenteric veins (fig. 2, 9). These veins, also paired and symmetrical, are smaller than the umbilicals. Although their point of entrance into the sinus venosus is the most mesial and ventral of all vessels entering the heart, the plane of the main trunk passes about midway betwcen the umbilical and post-cardinal veins, so that the course of the vessel as it approaches the sinus is deflected sharply forward and inward. Two divisions of this vessel may be recognized, an intra-hepatic portion which has entered into the formation of the sinusoids and is situated at the dorso-mesial angle of the liver. It thus comes into close proximity to the coelomic angle. The second or omphalic portion passes out upon the yolk sac, leaving the body through the external umbilicus. In this way, each omphalomesenteric vessel, in its intrahepatic portion, has its long axis parallel both with the umbilical and post-cardinal veins, but interposed between it and each of these channels are the mesial branches of the perimesonephroic plexus. No evidence of any distinctly mesenteric branch was found.

3. The post-cardinal veins (fig. 2,5). These are present as a pair of vessels of medium size which have become definite channels throughout their entire length. They hold their typical position dorso-lateral to the mesonephros and still retain part of the plexiform connection with the umbilical veins (fig. 2, 7). This connection becomes greatly reduced as the promontory is reached. The size of the vessel increases as it ascends to become confluent with the pre-cardinal, but before doing so it turns forward almost at right angles to its axial course and by this horizontal arm enters the duct of Cuvier. Immediately below this sharp forward bend, the post-cardinal receives a large tributary from the cephalic extremity of the perimesonnephroic plexus. In the greater part of its course many branches from the plexus join this vessel. At some points the vein has 
a tendency to reduplicate its channel; the redundant element then lies mesial to it. In the region of the promontory several small dorsal tributaries enter the vessel.

4. The pre-cardinal veins (fig. 2, 2). These vessels constitute the fourth pair of symmetrical channels and appear in the typical position of the early stages. The main trunk is parallel to the neural tube and descends toward the Cuvierian duct, into which it enters, after curving sharply forward and inward. It follows the direction of the neural axis cephalad, adapts itself to the cervical flexure, and turns forward nearly at right angles to its descending portion. In this way the vessel may be regarded as presenting two limbs, $a$, an arched or horizontal limb which is assuming the position of the vena capitis lateralis, and $b$, a straight or descending limb in the jugular line. The straight limb receives several small, dorsal tributaries whose development plays an important rôle in the genesis of the veno-lymphatics.

5. The perimesonephroic plexus (fig. 2, 8). This forms a dense network around the mesonephros throughout its entire length. It has its greatest density along the ventral surface of the organ. At many points the large mesonephroic sinuses communicate with the plexiform channels. The plexus becomes much reduced in size on the mesial and lateral surfaces of the mesonephros, where an irregular series of anastomosing channcls establish communication with the post-cardinal vein. During the course of development, the ventral portion of the perimesonephroic plexus takes part in the evolution of certain axial vessels; the mesial anastomosing branches give rise to the lateral portion of periaortic plexus (fig. 3, 46 and fig. 4, $46)$.

6. The umbilco-post cardinal plexus fig. 2,7 ). This connects the umbilical and post-cardinal veins. It represents the intermediate phase during which the umbilical vein has preserved its capacity as a drainage line for the body wall and is about to give this function over to the post-cardinal. In many places the plexus has already broken down and appears to be selecting the post-cardinal as its ultimate channel. 
Such evidence of lymphatic organization as this embryo affords confines itself to the primitive venous fundaments of the jugular lymph sacs. If these elements did not so nearly duplicate the conditions of the early ground plan of the sac in the cat, it would be difficult, without further material, to recognize their true significance. They appear as several dorsal tributaries in connection with the straight portion of the pre-cardinal vein, with the promontory and with the cephalic extremity of the post-cardinal vein. Three of these branches are related to the straight limb of the pre-cardinal, one to the promontory and one to the post-eardinal The tributaries in relation with the pre-cardinal vein are irregular and have the appearance of redundancies in the vein line. One in particular, the third and most caudal of the series, is larger and more irregular than the rest. Another characteristic of early lymph sac formation is the marked increase in size of the pre-cardinal vein and promontory as they draw together toward the Cuvierian duct. This augmentation does not appear to be in response to the entrance of new tributary lines, but, as in the cat, seems to be a redundant growth of the venous network prior to its differentiation into distinct venolymphatic channels. Upon these grounds, and especially because of their striking correspondence to the conditions observed in the cat, these structures may fairly be taken to represent the elements which determine the early or primary venous stage of lymph sac organization.

The venous organization of the 6 mm. embryo (fig. 5 and fig. 6 )

The advance observed in this embryo is characterized by the emergence of a definite sub-cardinal drainage line out of the perimesonephroic plexus and the disturbance of the bilateral symmetry in the umbilical veins. There are five sets of paired venous channels, the general disposition of whose course is parallel to the long axis of the body. The perimesonephroic and umbilico-cardinal plexuses have lost their definite outlines.

1. The omphalomesenteric veins (fig. 6, 9). Notwithstanding the fact that the cephalic portion of each vitelline vein has become 
involved in the formation of the hepatic sinusoids, it is still possible to recognize two well defined venous channels passing through the liver, parallel with the body axis and situated in the angle formed by the junction of the dorsal and mesial hepatic surfaces. The anterior walls of these channels are subject to great irregularities occasioned by their relations to the hepatic sinusoids; their dorsal and mesial walls are well defined. Each channel is situated opposite the coelomic angle, dorso-lateral to the gut tube, directly ventral to the sub-cardinal vein and ventro-mesial to the post-cardinal vein. The two intra-hepatic vitelline vessels not only drain the sinusoids of their respective sides but commumunicate with each other by several transverse anastomoses which follow a semi-circular course in front of the gut tube. The most cephalic of these anastomotic channels is the largest and lies at a level a little below the vitelline entrance into the sinus venosus. As it approaches this sinus, each vitelline vein undergoes a change in course, curving outward and forward, then upward and inward to a point slightly mesial to the entrance of the umbilical vein. The intra-hepatic vitelline channels may be traced caudad to a large sinus-like blood space situated immediately below the liver. This large sinus has been greatly augmented by the confluence of the two umbilical veins and the omphalic portions of the vitellines. From its position it may be conveniently referred to as the sub-hepatic sinus (fig. 6,11 ), which, in this embryo, receives blood from the large umbilical veins and a single omphalic vessel of medium size. It delivers blood to the hepatic sinusoids, and the two intra-hepatic vitelline channels, having a more ample communication with the channel of the right side. Two veins of small size appear in the gut wall in regions below the liver; their relations identify them as the mesenteric veins. The left mesenteric vein is the larger of the two; it establishes connection with the left intra-hepatic vitelline channel at a distance of $100 \mu$ cephalad of that vessel's departure from the sub-hepatic sinus. The right and smaller mesenteric vein joins the left vein by a semicircular anastomosis behind the gut at a point $300 \mu$ below the entrance of the latter vein into the left intra-hepatic vitelline channel. The follow- 
ing components may be distinguished in the omphalomesenteric drainage line.

a. The omphalic or vitelline element, a single vein which drains the blood from the yolk sac into the sub-hepatic sinus.

$b$. The intra-hepatic vitelline element, appearing as a right and left channel, of which the right is to persist as the hepatic portion of the post-cava, receiving the hepatic revehent veins and, during intra-uterine life, the ductus venosus; the left channel takes part in the development of the hepatic revehent veins and sinusoids. By its early association with the mesenteric veins, this vessel aids in the formation of the hepatic portal system of post-natal life.

$c$. The mesenteric elements, appearing in the gut wall as right and left veins, the left communicating with the left intrahepatic channel, while the right vessel gives its drainage to the left mesenteric by a semicircular anastomosis behind the gut. These latter elements give rise to the definitive portal system.

2. The umbilical veins (fig. 5,6), These vessels, in greater part, still retain their symmetrical arrangement, but the general venous symmetry of the earlier stage is now to some degree disturbed in the region in which the omphalic portion of the vitelline veins become confluent with the umbilical veins to form the sub-hepatic sinus. The significance of the umbilical veins below the sinus appears to be so different from that above it as to justify the distinction of infra-sinal and supra-sinal portions in either vein. The capacity of the infra-sinal portion is several times that of the supra-sinal. The left infra-sinal segment has increased greatly in size and, in places, is a double channel. The right infra-sinal segment is also double, but for a shorter distance. The supra-sinal segment of the umbilical vein is a relatively slender vessel, extending from the outer side of the sub-hepatic sinus to the sinus venosus. In its entire course cephalad it receives numerous anastomotic branches from the umbilico-cardinal plexus and is thus still Iargely concerned in drainage of the body wall. It aids in the return of blood from the sub-hepatic sinus and so affords two direct passages 
from the placenta to the heart, pending the establishment of the well defined ductus venosus.

3. The post-cardinal veins (fig. 5, 5). These vessels occupy the typical post-cardinal position. They may be traced caudad as far as the cloaca and there lose their identity in an indefinite plexus. Followed cephalad, each vessel is seen to attain its maximum diameter at the level of the middle of the mesonephros. They still give evidence of the early influence of the perimesonephroic plexus; in several regions a channel is observed lying parallel to the main vessel and continuous with it above and below. The redundant element may be ental or ectal in position. The genesis of this intermediate cardinal element is not yet entirely clear. Like the sub-cardinal vein, it seems to represent the general process by which definite channels are evolved from more primitive plexus formations along the lines of axial growth and drainage. The cephalic portion of the post-cardinal vein is still intimately related to the supra-sinal segment of the umbilical vein by branches of the umbilico-cardinal plexus. In the region of the promontory, each vessel increases in size and receives a number of dorsal tributaries.

4. The sub-cardinal veins and the perimesonephroic plexus (fig. $5,12)$. One of the characteristic changes in this stage is the development of a definite sub-cardinal vein out of the perimesonephroic plexus. This vein is a slender vessel with here and there a remnant of the former plexus draining into it. This is particularly the case about the lower pole of the mesonephros where the plexus is still rich and shows a tendency to give rise to other axial lines besides the sub-cardinal channel. Here it is possible to recognize a longitudinal drainage line which is being selected along the inner aspect of the plexus, mesial to the subcardinal itself and ventro-lateral to the aorta. This element is in the position of the cardinal collateral channel of McClure. Because of its course and relations, three portions of the subcardinal vein may be recognized. 1. The caudal vertical portions 2 , the middle or horizontal portion and 3 , the cephalic vertical portion. The caudal vertical portion begins as a slender vessel from the caudal extremity of the peri-mesonephroic plexus; 
it passes cephalad along the ventro-mesial surface of the mesonephros, having its long axis parallel with the aorta. Upon reaching the level of the sub-hepatic sinus the vessel swings dorsad and slightly lateral so that its axis is now turned almost at right angles to its caudal portion. The position which it now occupies distinguishes it as the middle or horizontal portion of the vein. In this portion of its course the vessel closely follows the direction of the intra-hepatic segment of the vitelline vein as the latter is sweeping dorso-cephalad away from the sub-hepatic sinus. The two vessels are still completely separated by the coelom with a measured distance of $10 \mu$ between them. The angle determined by the junction of the caudal and middle portions of the vein lies in a direct line with the intrahepatic portion of the vitelline vein, so that the projection caudad of the axis of the latter vessel would coincide with the axis of the caudal portion of the sub-cardinal vein, and would thus foreshadow the axis of the future post-cava (on the right side). It is not possible to state that the region of closest approach is the region of the final confluence of these two vessels, but it. seems probable from the relations of the sub-hepatic sinus, that the ductus venosus, intrahepatic vitelline and sub-cardinal veins of the right side unite at this, rather than at some more cephalic point. The cephalic vertical portion continues the vein cephalad and is the smallest as well as the shortest of the three divisions. It taps the post-cardinal vein $200 \mu$ above the cephalic pole of the mesonephros. It is parallel to the intra-hepatic portion of the omphalomesensenteric vein, from which it is separated by a mean distance of $20 \mu$.

5. The pre-cardinal veins (fig. 5, 2) and veno-lymphatics. The general arrangement of the pre-cardinal veins has undergone no marked change. The vessels still present an arched and a a straight limb. There has been, however, considerable modification in the character of the dorsal tributaries. These have expanded and become confluent in several places. The expansion has continued after confluence has taken place and the channels have been converted into irregular spaces. The four dorsal tributaries to the pre-cardinal vein have all united, while 
the tributaries coming into the promontory and cephalic portion of the post-cardinal have joined to form a large blood space. The tendency of the pre-cardinal and post-cardinal veins to increase in size as they approach the duct of Cuvier is still evident. On the right side there are clear signs of a beginning fenestration in the base of the pre-cardinal, thus indicating the inception of the para-pre-cardinal line.

Marked changes are met with in passing from the primitive orgarrization of the $6 \mathrm{~mm}$. embryo to the condition of the $20 \mathrm{~mm}$. embryo. As touching upon the stages intermediate between the two, reference will be made to the $13 \mathrm{~mm}$. specimen. A noteworthy acquisition in the $20 \mathrm{~mm}$. embryo is found in the now fully developed lymph sacs, and also in the formation of the main segments of the systemic lymph channel. These two elements are as yet entirely distinct and separate. The plan of venous drainage foreshadowed in the $6 \mathrm{~mm}$. embryo has been carried well on towards completion. In this process a single post-cava has been acquired as far as the inter-renal anastomosis while below that level, two large symmetrical channels, representing the cardinal collateral veins, coöperate in the formation of a double post-cava.

\section{The lymphatic organization in the $20 \mathrm{~mm}$. embryo (fig. 7)}

In the $20 \mathrm{~mm}$. embryo, the jugular lymph sacs (fig. 7, 25) are situated in the neck region, one on either side, on the lateral aspect of the great vessels and nerves. Each sac has a general wedge shape, with its base looking inward and forward, while its edge lies between the vertebral column and the dorso-lateral surface of the body. Its greatest diameters are attained about midway between its cephalic and caudal poles. The 3rd, 4th, 5 th and 6th cervical ganglia lie dorsal to the sac. The third cervical nerve traverses its cephalic pole, the sixth nerve passes beneath its caudal pole, while the fourth and fifth nerves go. directly through it. The right sac is $1.61 \mathrm{~mm}$. in length, the left sac $1.73 \mathrm{~mm}$. The maximum ventro-dorsal diameter of the right sac is $1.68 \mathrm{~mm}$., that of the left sac being $1.6 \mathrm{~mm}$. The 
maximum transverse diameter of the right sac is $.54 \mathrm{~mm}$., that of the left sac is $.48 \mathrm{~mm}$. It will be convenient to describe the structure as having a body with caudal and cephalic processes.

The body of the lymph sac (fig. 7, 25). This portion of the sac appears as a prominent feature of cross sections in the neck region. The walls of the sacs are thinner than those of the veins. The mesial and ventral walls are smooth and regular, the lateral wall presents many irregular projections. The broad ventral portion of the sac lies directly back of the jugular vein (fig. 7, 85). Mesially it is in relation with the carotid artery, the vagus and sympathetic nerves, but separated from them by an extensive plexus of venous channels draining into the jugular system. In its subsequent development, this plexus allies itself with the lymphatic system.

Processes of the sac. The contour of the sac becomes irregular in several regions by prolongations from its walls. These prolongations serve as the processes by which the sac acquires its ultimate connections with the venous system and the systemic lymphatics. From the cephalic pole a large number of processes reach upward into the head region and end blindly. Some of these prolongations serve to connect with the systemic lymphatic trunks from above. The caudal processes are larger and show a more definite arrangement. Their number and disposition differ on the two sides. This difference depends upon the relations which each sac bears to the adjacent veins. The left sac is still freely connected with the jugular vein; the right sac is entirely cut off all venous connection. The left sac is typical of the conditions in the late veno-lymphatic period. The right sac affords a good example of the pre-lymphatic stage. Due to its free communication with the left jugular vein, the left sac is filled with blood. Caudally, it is divided into two main processes, one of which turns mesad and ventrad in the direction of the jugular vein, the ventro-mesial process; the other continues caudad in line with the general axis of the sac, the dorso-lateral process. The ventro-mesial process enters directly into the vein, On the right side the sac has already been emptied of blood and has lost connection with the jugular vein. The dorso-lateral process (fig. 7,26 ) is present on each side. It does not connect 
directly with the veins but proceeds caudad to form three other processes, namely, the lateral process or subcutaneous duct, the dorsal descending process or thoracic duct approach (fig. $7,26 a$ ) and the ventral descending or broncho-mediastinal approach. The ventral and dorsal descending processes become divergent immediately above the cephalic vein; the ventral process passes caudad on the ventro-lateral aspect of the jugular vein to join the broncho-mediatinal systemic channels on the right side. On the left this connection is not completed. The dorsal descending process extends a short distance caudad, dorsolateral to the thyreo-cervical artery to end blindly.

Organization of the systemic lymphatic drainage lines. The evidence concerning the development of the lymph sac in Tragulus shows that this structure is derived from the venous system. In its early stages the sac is wholly independent of the systemic lymphatics. Subsequently it joins with the systemic lymphatic channels, and thus serves as the connecting link between these channels and the venous system. In the material studied it was impossible to discern any genetic relation between the developing systemic lymphatics and the veins. Such regions as gave the earliest pictures of the organization of the systemic lymphatics revealed these elements as independent mesenchymal spaces, at first presenting the form of a plexus. By a process of expansion and confluence this plexus comes to form definite channels. In the $20 \mathrm{~mm}$. embryo development has advanced too far to offer anything that is conclusive as to the actual histogenesis of these lymph spaces. The process referred to as confluence and expansion is not carried on with the same degree of rapidity or effectiveness in all regions of the embryo; it confines its activities to certain selected districts which remain, for some time, separate. The systemic lymphatic channels arise from three major segments which, because of their relations to the venous system, may be termed the azygos, pre-azygos and postazygos segments, corresponding to similar segments in the cat as recently described by Huntington ('10).

1. The azygos segment (fig. 7,28 ). It is in this segment that the systemic lymphatic channels have attained their greatest development. Longitudinally the segment reaches caudad from 
the azygos-Cuvierian junction to a level slightly above the interrenal anastomosis. It is notable for its unusual size as well as for the striking resemblance it bears to the reptilian type of axial lymph channel (fig. 9; 28). On approaching its cephalic extremity the channel breaks up into a rich plexus (fig. 8, 50). The same is true of its caudal extremity. The vessel on the left side is the larger. It is situated ventro-mesial to the azygos vein and dorso-lateral of the aorta. The right channel holds the same relative position. After proceeding a short distance caudad these two parallel channels rapidly expand and become confluent across the median line behind the aorta. The azygos segment interposes itself between that vessel and the two azygos veins, which latter are connected with each other by anastomos. ing vessels passing behind the aorta. The relations of the azygos segment to the other large channels are illustrated in cross section in fig. 9.

2. The post-azygos segment (fig. 7, 29). This portion of the systemic lymphatic channel pertains to the abdominal region where it appears as an irregular vessel, at times double and again fused, behind the aorta. It continues downward in this condition to the iliac bifurcation where it becomes a considerably dilated, single vessel again bifurcating at its caudal extremity. At the point of this bifurcation it alters its relations in such a manner as to lie lateral to the iliac vein, taking up the ultimate position of the ilio-lumbar lymphatic trunks. At its cephalic extremity it ends in a plexus which has already established several connections with the plexus at the caudal extremity of the azygos segment.

3. The pre-azygos segment (fig. 7, 30 and 31). In this portion of the systemic lymphatic channel the process of expansion is apparently less active than elsewhere. Two general lines of development may be traced, one on the right in relation to remnant of the right pre-cardinal vein and aorta, the other on the left in relation to the large brachio-cephalic arterial trunk. Each line presents a cephalic and caudal element. On the right side the caudal element communicates with the plexus at the cephalic end of the azygos segment (fig. 8,50), and from here extends cephalad 
between the aorta and pre-cardinal vein as far cephalad as the arch of the aorta. The cephalic element begins as a plexus at the bifurcation of the brachio-cephalic artery and continues cephalad dorso-lateral of the jugular vein as far as the jugulo-subclavian junction. At this point it is separated by an interval of approximately $0.1 \mathrm{~mm}$. from the blind end of the dorsal descending process of the lymph sac (thoracic duct approach). The pre-azygos segment on the left side is even more divided, for although it presents a cephalic and caudal division, each of which appears as a clear cut channel, it was impossible to detect any connection between these two divisions on the one hand and the azygos segment on the other. It ends blindly above and appears to have no connection with the thoracic duct approach of the sac, from which it is separated by an interval of about $0.1 \mathrm{~mm}$. Its caudal end is also independent of any connection. The caudal division begins as a distinct channel at the derivation of the internal mammary artery and extends almost as far caudad as the junction of the brachio-cephalic trunk with the aortic arch. So that, above the azygos segment, the line along which the thoracic duct is destined to develop its connection with the duct approach of the lymph sac consists of two as yet independent elements, the cephalic and caudal divisions of the left preazygos segment.

A summary of the systemic lymphatic organization shows that the following elements must be recognized in the future line of the thoracic duct:

(a). The azygos segment (figs. 7, 28 and 9, 28). A spacious sinus-like channel, in places entirely surrounding the aorta and ending at either extremity in a plexus, in many regions resembling the peri-aortic lymphatic sinus of reptiles.

(b. The post-azygos segment,(fig. 7, 29), a series of alternating plexiform and sinus-like channels, connected cephalad with the caudal plexus of the azygos segment.

(c). The pre-azygos segment,(fig. 7, 30 and 31), consisting on the right side of two independent divisions, the cephalic and caudal, of which the latter is connected with the cephalic plexus of the azygos segment while the former has not yet established 
communication with the thoracic duct approach of the lymph sac. On the left side, the two divisions are also present, but neither has made connection with other parts of the lymphatic system.

Lymphatic organization in the $23 \mathrm{~mm}$. embryo

Axial lymphatic organization has been carried to its consummation in the $23 \mathrm{~mm}$. embryo. The imperfectly crystallized conditions of the next younger specimen have already marked out the line along which this development would proceed.

Body of the lymph sac (fig. 10). The body of the sac on both sides lies in front of the $3 \mathrm{rd}, 4 \mathrm{th}$, and 5 th cervical ganglia, the 6th ganglion and the interspace above it lying entirely below the caudal limit of the vesicle. The long body axis now bears the ratio of 17 to 1 to the long axis of the lymph sac, whereas in the $20 \mathrm{~mm}$. embryo this ratio was 10 to 1 . Measurements of the sac as computed from the mounted sections show that this decrease in size is not merely relative but absolute, as the following values of the long axes show:

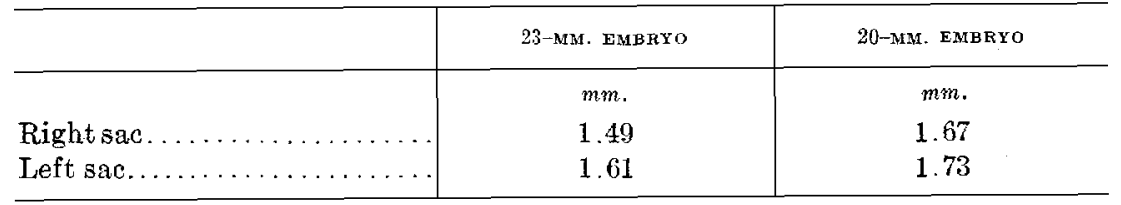

The ventro-dorsal and transverse diameters also show a decrease. That this attenuation has chiefly affectcd the more ventral portion of the sac is shown by the fact that the two nerves (4th and 5 th cervicals) which in the $20 \mathrm{~mm}$. embryo passed through the sac have now freed themselves, while it also appears that the process which released them has at the same time produced a neck in the sac itself. By this neck the sac approaches the jugular vein and attains its ultimate systenal lymphatic and venous connections. It will be obvious, therefore, that this cervical portion corresponds in general to the caudal extremity in the sac of the next younger specimen.

Processes of the sac. Several of the cephalic processes maybe traced for a considerable distance into the head region and un- 
doubtedly denote the connections of the sac with lymphatic trunk lines of the head. The main interest with reference to these processes centers about those which are derived from the caudal extremity or what may be termed the cervix of the sac Upon reaching the level marking the entrance of the cephalic vein into the jugular, the cervix of the sac breaks up into four processes, namely:

1. The dorsal process which extends dorsad accompanying the cephalic vein and receives the dorsal somatic tributary of the sac, the subcutaneous duct.

2. The mesial process, the now much reduced primary venolymphatic connection which extends mesad dorsal to the jugular vein but does not tap into it.

3. The dorsal descending process which in the $20 \mathrm{~mm}$. embryo was designated the thoracic duct approach and which has now acquired its full connection with the preazygos segment of the duct, especially on the left side. This process descends along the dorso-lateral surface of the thyreo-cervical artery.

4. The ventral descending process which affords communication with the broncho-mediastinal channels. It appears in a position ventral to the thyreo-cervical artery. As this process enters the sac it forms an acute angle with the dorsal descending process which lodges the cephalic vein as it is opening into the jugulo-subclavian junction. In addition to the broncho-mediastinal approach, the ventral descending process has developed still a third, the jugulo-subclavian approach. This is a slender prolongation from the mesial side of the process which, upon reaching the jugulo-subclavian angle, forms a direct communication with the venous system. This is the so-called secondary venous tap of the lymphatic into the venous system and by its establishment determines the transition from the prelymphatic to the lymphatic stage. The secondary tap is made in a characteristic manner. From the wall of the vein at its jugulo-subclavian junction a process which has the appearance of a tubular redundancy pushes its way cephalad between the lateral vein wall and the mesial wall of the sac. After a short distance it meets and opens into the jugulo-subclavian approach of the lymph sac thus producing a channel between the latter and the 
venous system. The venous orifice of this duct-like structure is wide; the saccular orifice is elongated and narrow, while the duct itself is placed between the walls of the sac and the vein. This arrangement makes it appear that distension of the vein would act on the jugulo-subclavian approach in such a way as to produce a valvular effect. By this means the sac has acquired its ultimate connection with the venous system (fig. 11, $A, B$, and $C$ ).

The systemic lymphatic drainage line. The transition from the conditions of the systemic lymphatic organization of the 20 $\mathrm{mm}$. embryo to those of the $23 \mathrm{~mm}$. is characterized by a confluence of the several previously established segments, with the result that the thoracic duct is now a continuous channel and at the same time has upon the left side, acquired connection with the lymph sac.

The azygos segment. This portion of the systemic lymphatic line gives evidence of the least change of character. It is still a capacious channel situated dorsal to the aorta, in places surrounding the vessel. If changed at all, it has somewhat lost in capacity, especially because its periaortic plexuses are less rich and numerous. In relation to the azygos veins, it still is interposed between them and the aorta. The plexuses which, in the early conditions, were observed at its cephalic and caudal extremities have given place to definite channels (fig. 12). From the cephalic plexus there has arisen a single large trunk which is paralleled by a second small lymph vessel, both of which pass over into the pre-azygos segment. The caudal plexus develops two channels which communicate with the post-azygos segment.

Pre-azygos segment (fig. 12). Here the greatest change has occurred, for the plexiform and irregular channels of the earlier pre-azygos segment have become defined as two parallel trunks. The larger of these is the more constant and apparently represents the main line of drainage. Upon the leftside the confluence of the several divisions of the pre-azygos segment has been carried so far as to form a complete connecting vessel in communication with the dorsal descending process of the lymph sac of that side. On the right side this confluence is not as com- 
plete. The cephalic division of the pre-azygos segment has met and fused with the thoracic duct approach of the sac. The caudal division is still independent.

Post-azygos segment (fig. 10, 29). This segment has also attained more definite outline. Its caudal dilatation is larger and its ilio-lumbar appendages more extensive, so that upon the left side there is an uninterrupted thoracic duct line, which has resulted from the fusion of the pre-azygos, azygos and postazygos segments. The right duct line is still incomplete. The ventral descending process of the sac on both sides has already established connection with the truncus broncho-mediastinalis. In the main, this trunk is still a dense plexus situated ventral to the thymus; in several places, however, it loses its plexiform character to become a distinct channel. Retaining these general relations to the thymus, it passes to the caudal extremity of that organ, where it undergoes considerable reduction, but may be traced across the aortic arch to the root of the lung.

\section{THE VENOUS ORGANIZATION IN THE LATE FMBRYONIC STAGES}

The advance in the venous organization in the $20 \mathrm{~mm}$. embryo depends on a modification in the relations between the umbilical and omphalomesenteric veins. Coalition of the right sub-cardinal with the right emphalomosenteric has produced a definite post-caval system as far caudad as the renal anastomosis. Below this level the cava arises in a manner somewhat different from that observed in the majority of mammals already studied.

\section{Renal anastomosis and cardinal collateral veins}

Upon reaching the level of the kidneys, the post-caval drainage line becomes greatly expanded to form a large, irregularly quadrilateral channel situated in front of the aorta. This large channel establishes the renal anastomosis and, from its position, may be termed the inter-renal segment of the post-cava. It presents two cephalic and two caudal angles. From its right cephalic angle the post-caval drainage line is continued toward the heart by means of the right sub-cardinal vein. Its left cephalic angle receives the left suprarenal vein. The renal vein 
enters the inter-renal segment immediately below the cephalic angle (fig. 13, 57 ).

Two vessels of equal size enter the inter-renal segment, one at either caudal angle. They are practically parallel to each other, are placed ventro-lateral to the aorta and separated from each other by a mean distance of $60 \mu$. Caudally they arise from the junction of the internal and external iliac veins. The proximity of these two parallel channels to the median line, their position ventral to the aorta and mesial to the ureters makes it probable that they are derivatives of the ventro-mesial element of the peri-mesonephroic plexus and hence should be considered the cardinal collateral channels (fig. 13, 21).

Immediately above the entrance of each cardinal collateral vessel, a vein from the mesonephros empties into the inter-renal segment. This mesonephroic vein subsequently becomes the sex vein and will hereafter be referred to by that term (fig. 13, 40).

Caudad of its sub-cardinal portion, the axial drainage line is therefore made up as follows, beginning from the confluence of the internal and external iliac veins.

1. The two cardinal collateral veins, constituting the so-called paired portion of the post-cava (fig. 13, 21).

2. The inter-renal segment, situated directly ventral to the aorta and between the kidneys. It receives the cardinal collateral and sex veins at its caudal angles while the renal veins empty into it by its cephalic angles: At its right cephalic angle it passes over into the sub-cardinal portion of the post-cava (fig. 13, 59).

The relative dimensions of the two portions change considerably in the further development of the post-cava; the following tabulation gives the length of the two segments in the older embryos as compared with the adult conditions.

\begin{tabular}{|c|c|c|c|}
\hline & 20-MM. ЕMBRYO & 23-MM. ЕMBRYO & ADULT \\
\hline & $m m$. & $m m$. & $m m$ \\
\hline Length of inter-renal segment.... & 0.71 & 0.75 & 65 \\
\hline $\begin{array}{l}\text { Length of paired portion (cardinal col- } \\
\text { lateral) } \ldots \ldots \ldots \ldots \ldots \ldots \ldots \ldots\end{array}$ & 0.14 & 1.25 & 49 \\
\hline Distance between renal and sex veins...... & 0.26 & 0.30 & 54 \\
\hline
\end{tabular}


From these figures it appears that the ratio of the inter-renal segment to the paired portion of the cava (cardinal collaterals) is 1 to 1.6 in the $20 \mathrm{~mm}$. embryo as against 1 to 0.75 in the adult animal. In other words, if the increment of growth has remained constant in the inter-renal segment, it has been reduced one half in the cardinal collateral vessels while passing from the 20 $\mathrm{mm}$. stage to adult. These facts make it clear that longitudinal expansion of the inter-renal segment plays an important rôle in determining the position and relations of the post-renal segment of the cava. This assumption is further borne out by the fact that the distance between the sex veins and the renal veins progressively increases in passing from the embryonic stages to the adult.

\section{The pre- and post-cardinal veins}

The pre-cardinal veins may still be identified almost in their entirety even in these late stages. In the greater part of the neck they constitute a pair of channels, the internal jugular veins. High up in their cephalic portion, they receive a short trunk which has resulted from the confluence of the temporofacial and internal maxillary veins. This trunk represents the external jugular vein. As the two internal jugular veins approach the thorax they become confluent and form a single large vessel. It is into this confluent element that the sub-clavian, cephalic, internal mammary and vertebral veins enter. On passing into the superior mediastinum the single vessel again becomes a double channel. The vessel on the right is much the larger. This portion of the jugular system represents the pre-cava which, after becoming much reduced in size, enters the heart. The left channel proceeds further caudad and finally joins the left post-cardinal vein to form the duct of Cuvier.

The left post-cardinal vein participates in the formation of the left azygos vein. During this process that redundant cardinal channel, earlier observed in the perimesonephroic plexus and referred to as the intermediate element, seems to take a prominent part. In the cephalic portion of the azygos major vessel, the original post-cardinal channel determines the ultimate 
vein line, but in those regions corresponding to the perimesonephroic plexus of the younger stages; the intermediate element is obviously the selected channel. The relations of this element to the aorta in the $6 \mathrm{~mm}$. specimen indicate the future line of the azygos vessel. In the $13 \mathrm{~mm}$. embryo the intermediate element has become a more prominent channel than the post-cardinal. A right azygos vein, corresponding in position to the left vessel, is formed in like manner, except that it establishes its ultimate drainage connections by a series of cross anastomoses with the left vein. These anastomoses, at first, are diffuse and, in the $20 \mathrm{~mm}$. embryo, appear as irregular channels between the two azygos lines. The most cephalic channel is well defined and larger than the rest. In the $23 \mathrm{~mm}$. embryo the formation of distinct cross vessels has been carried much further so that these inter-azygos connecting lines are now arranged in segmental series, are twelve in number, and occur at the junction of each dorsal segmental vein with the azygos vessel of its respective side (fig. 10, 62). Another set of anastomosing vessels serves to connect the two azygos channels with the sub-cardinal and cardinal collateral lines. These anastomotic vessels are placed along the sides of the aorta and thus correspond in their relations to the mesial branches of the perimesenephroic plexus observed in the younger stages. Two sets of these vessels may be distinguished, a cephalic anastomosis which traverses the anlage of the supra-renal body and undergoes a gradual reduction in passing from the $13 \mathrm{~mm}$. to the $23 \mathrm{~mm}$. stage. This plexus forms a connection between the azygos vein and the corresponding side of the post-cava in its inter-renal segment. The second plexus is much more extensive. It establishes a communication between the azygos veins and cardinal collateral portions of the post-cava (fig. 14, 61). The significance of this connection in its bearing upon the possibilities of post-caval formation will subsequently be discussed. That it gradually diminishes in significance as growth proceeds is witnessed by the fact of its actual reduction in passing from the $13 \mathrm{~mm}$. to the $23 \mathrm{~mm}$. embryo. The post-cardinal veins thus concern themselves with the azygos system, allowing the selection of the caval drainage line to fall 
upon the other channels. The venous plexus between the preaortic and post-aortic veins becomes so extensive as to completely invest the aorta except for a small interval immediately in front, on either side of the median line. As it approaches the levels marking the derivation of the hypogastric arteries the plexus becomes more voluminous and finally communicates with the iliac trunks.

From the conditions of these embryonic stages it is obvious that the venous return from the internal and external iliac veins depends upon a large peri-aortic plexus rather than upon discrete venous channels. The increasing prominence of certain axial channels in this plexus clearly indicates the process by which the plexus itself is to be replaced by veins in the line of the longitudinal growth of the body. The course of these axial channels is parallel to the long body-axis; two are placed ventro-lateral to the aorta, the cardinal collateral veins; two are situated dorsolateral to the aorta, the post-cardinals. At the indeterminate stages represented by the $20 \mathrm{~mm}$. and the $23 \mathrm{~mm}$. embryos the internal and external iliac veins may select one of several possibilities for the continuance of their drainage lines toward the heart. They may choose either or both of the post-cardinal veins to the exclusion of the cardinal collaterals, so that the venous blood would reach the inter-renal segment of the cava by the plexiform channels of the inter-renal post-cardinal plexus. They may select both cardinal collaterals to the exclusion of the post-cardinals and so establish a communication with the interrenal segment of the cava. The adult conditions, showing that the post-renal segment of the cava is pre-aortic in position, clearly demonstrate that the selection has fallen upon the cardinal collateral veins and that the post-cardinals play no part in the formation of this portion of the cava.

These possibilities of selection which must be reckoned with in discussing the post-renal cava in Tragulus emphasize again the statement of Schulte ('09) that

homonymous venous channels are not necessarily morphological equivalents but are rather homodynomous, agreeing in function because they drain similar areas:- and it thus appears that the anatomicalname of 
veins designate not morphological but physiological units. The term post cava only indicates a hydro-dynamic line. The variously named cardinals are merely dilated portions of the reticulum along the major hydro-dynamic lines, which, responding to the large volume of blood they transmit, dominate the picture.

Although the facts cited above account for the acquisition of a pre-aortic post-renal segment of the cava in the adult Tragulus, they do not furnish a complete explanation of the process by which the ultimate relations of this vessel are attained. In the $20 \mathrm{~mm}$. and $23 \mathrm{~mm}$. embryos the post-renal segment of the cava presents two portions, each of which is pre-aortic in position, namely, the paired portion and the unpaired portion. The unpaired portion in these stages, constitutes about one-third of the entire post-renal segment of the cava (fig. 13, $A$ and $B$ ). In the adult, while the paired and unpaired elements still enter into the formation of the post-renal segment, their proportions have greatly changed. The unpaired portion instead of being onethird as long as the paired portion is now six times longer. In other words five-sixths of the post-renal segment of the cava is represented in the adult by a single unpaired pre-aortic channel, the remaining one-sixth being represented by the paired portion (fig. 1). This marked change in proportion may be due to one of three possibilities; 1 , the fusion of the two cardinal collateral veins across the median line in the cephalic two-thirds of their course; 2 , a caudal migration of the angle of confluence of the cardinal collaterals; and 3 , the longitudinal expansion of the inter-renal segment alone. The position and relations of the sex veins considerably lessen the difficulties in deciding which of these processes is the active one. It has already been shown, in the older embryos, that the renal veins mark the cephalic limits of the inter-renal segment while its caudal limits are indicated by the sex veins. The portion of the cava between these limits, therefore, must be considered the inter-renal segment in all stages. Upon this basis, the change in proportion of the two elements of the post-renal cava, observed in passing from the embryonic to the adult stages, may be explained by the longitudinal expansion of the inter-renal segment. The ultimate wide 
separation between the renal and sex veins seems to indicate that this was the process by which the post-renal cava has been changed from an embryonic channel in greater part paired to an adult vessel in greater part unpaired. The probability of this explanation is further sustained by the fact that the increment of growth from the early stages has favored the inter-renal segment (see page 213). The relations between the length of the post-renal segment of the aorta and that of the inter-renal segment of the cava also show changes which are significant in this connection. The measurements of the aorta were taken from the point of derivation of the right renal vein to the iliac bifurcation; those of the inter-renal segment from the entrance of the right renal vein to the point of confluence of the two cardinal collateral veins.

In the $20 \mathrm{~mm}$. embryo the length of the inter-renal segment of the cava was 0.33 that of the post-renal segment of the aorta. In the $23 \mathrm{~mm}$. embryo this value has increased to 0.40 and in the adult to 0.87 . Thus there has-been a relative increase in the rate of growth in the inter-renal segment of the cava as compared with the post-renal segment of the aorta.

The change in the relations of the sex veins and arteries is further evidence of this relative increase in the inter-renal segment of the cava. Both of the older embryos show the sex veins and arteries in close relation to each other (fig. 13, $A$ and $B$ ). The veins enter the inter-renal segment practically in common with the entrance of the cardinal collateral veins. The sex arteries arise separately from the aorta at a level only slightly caudal to that of the veins. The adult specimen in the Columbia collection shows the sex arteries arising from a short common trunk given off from the aorta at a point $1.5 \mathrm{~cm}$. above the iliac bifurcation, while the sex veins enter the common iliac veins (paired portion of the post-cava) $4 \mathrm{~mm}$. below the point of entrance of these latter channels into the unpaired portion of the post-cava (fig. 1). Thus the sex arteries, which in the embryo arise from the aorta caudad of the sex veins, in the adult arise from a level distinctly cephalad of these veins. This marked change in relations appears to have its explanation in the relatively more rapid 
longitudinal growth of the inter-renal segment of the cava as compared with the post-renal segment of the aorta. The shifting of the sex veins from their more primitive point of inosculation may be due to a caudal migration of the angle of confluence of these vessels with the post-renal segment of the cava or it may be the result of certain mechanical changes due to the caudal migration and descent of the testis.

The intra-hepatic portion of the right omphalo-mesenteric vein has gained ascendency over all the venous spaces of the liver and appears as a definite channel situated in the right dorsomesial angle of that organ. It constitutes the hepatic portion of the post-cava. At the cephalic pole of the liver the vessel is large, receiving, in this region, the two major revehent trunks which drain the hepatic sinusoids. Immediately below the inosculation of these revehent vessels the cava diminishes in size, taking up as it proceeds caudad, several lesser, hepatic revehent tributaries. When the caudal pole of the liver is reached the vessel swings slightly mesad and dorsad, to pass over into the sub-cardinal portion of the cava. The mesenteric portion of the omphalomesenteric vessel has now become the portal vein and drains into one of the largest advehent branches of the umbilical channels. The post-caval drainage line thus utilizes the right intra-hepatic portion of the omphalomesenteric vein in passing through the liver, and the right sub-cardinal vein as far caudad as the inter-renal segment.

The umbilical drainage system presents itself as the typical single channel of foetal life. It makes its way through the umbilical fissure of the liver and then enters that organ. In the liver it breaks up into the rich plexus of the umbilical portal system. The ductus venosus is given off from one of the main stems of this plexus and passes obliquely upward to enter the post-cava in common with the confluence of the major hepatic revehent veins. These observations apply equally to the $20 \mathrm{~mm}$. and $23 \mathrm{~mm}$. embryos. 
SUMMARY

The development of the axial lymphaties in Tragulus presents the following characteristics:

1. Two distinct anlagen, one for the lymph sac and the other for the systemic lymphatics.

a. The lymph sac is derived from the venous system; passes from the primary venous into the veno-Iymphatic stage, at the end of which period it loses all connection with the veins and so enters upon its pre-lymphatic stage. Ultimately it establishes a secondary connection with the venous system and so becomes definitely lymphatic.

b. The axial systemic lymphatics develop in three distinct portions, namely the azygos, pre-azygos and post-azygos segments. The exact histogenesis of these segments could not be determined, but they convey the impression of plexiform channels arising independently in the mesenchyme and then rapidly expanding into discrete axial vessels. No connection between these segments and the veins was observed at any point. By confluence the segments became integrated to form the axial systemic lymphatics.

2. The final union of the two distinct anlagen determines the completed axial lymphatic line. In this manner the lymph sac becomes intermediary in establishing a communication between the venous and peripheral lymphatic system, a mode of organization which resembles that of the cat and so, no doubt, the general ground plan in mammals.

Advancing from the stage of symmetrical channels, the venous development is much concerned with modifications in the perimesonephroic plexus. This vascular network, bearing intimate relation to the mesonephros, is subsequently converted into such distinct channels as the sub-cardinal and cardinal collateral veins which have adapted themselves to the general line of axial growth.

These facts seem to sustain the proposition that all definite venous channels have their inception in a plexus and emerge from this plexus as definite veins, under the influence of certain hydro-dynamic factors, which are in the interest of most efficient 
venous return. Lest it be argued that the perimesonephroic plexus from which the above named vessels arise is a special case in Tragulus, it may be stated that this plexus has already been described by Brown ('11) in cat embryos, and has been observed by the writer in several sauropsid forms (chick and scleroporus embryos). The organization of the post-renal segment of the cava also appears to be an instance of the emergence from a plexus of selected axial channels; in this case the channels happen to be the cardinal collaterals. The plexus itself surrounds the aorta; the cardinal collateral vessels mark its ventral limits; the dorsal limits are formed by the post cardinals. A pre-aortic post-renal segment of the cava is established in part by the selection of the cardinal collateral veins as axial channels and in part by a marked longitudinal expansion of the inter-renal segment. These conditions observed in Tragulus definitely ally its post-cava with the marsupial type. The similarity thus established between the venous organization of this aberrant ungulate and that of the marsupials has a clear phylogenetic significance. It does not, however, shed much light on the more fundamental problems involved in the development of the postcava. In fact, it merely serves to open the question as to what hydro-dynamic and other mechanical factors must control the selection of the ultimate venous drainage channels in the axial line of the body.

In conclusion, the writer desires to acknowledge his indebtedness and express his appreciation to Professor Huntington for his direction and assistance in preparing this paper. 


\section{LITERATURE CITED}

BEDDARD, F. E. 1907 A preliminary note upon some characteristics of the venous system of Tragulus meminna and allied genera. Anat. Rec., no. 5 of Amer. Jour. Anat., vol. 7, no. 1, p. 111.

Brown AIFRED JEROME 1911 A note on postcardinal omphalomesenteric communications in the adult mammal. Anat. Rec., vol. 4, no. 12, p. 425.

Huntington, Geo. S. 1910 The genetic principles of the development of the systemic lymphetics vessels in the mammalian embryo. Anat. Reo., vol, 4 , no. 11, p. 399.

Huntington, Geo. S., and MoCudre, C. F. W. 1910 The anatomy and development of the jugular lymph sac in the domestic cat (Felis domestica). Amer. Jour. Anat., vol, 10, no. 2, p. 177.

MoClurk, C. F. W. 1903 A contribution to the anatomy and development of the venous system of Didelphis marsupialis. Part 1. Amer. Jour.Anat., vol. 2 , no. 3 , p. 371 .

1906 The post-cava of an adult Indian Chevrotain (Tragulus meminna, Erxleben). Anat. Anzeig., Bd. 29, No. 13.

Schulte, Hermann vox W. 1907 The range of variations in Monotremes and Australian Marsupials. Amer. Jour. Anat., vol. 6, no.3, Proceedings, p. 35 .

Schulta, Hermann ron $W$, and Truney, Frederick. $1909 \Lambda$ note on the organization of the venous return with especial reference to the iliac veins. Anat. Rec., vol. 3 , no. 11, p. 555 . 


\section{PLA'TE 1}

\section{EXPLANATION OF FIGURE}

1 Adult Tragulus meminna from a dissection in the study collection of the Department of Anatomy, Columbia University, showing the pre-aortic position of the post-cava. 24, aorta; 34 , ureter; 36 , internal iliac vein; 37 , external iliac vein; 38 , common iliac vein (paired portion of post-cava); 39 , unpaired portion of post-cava; 40 , sex vein; 41 , spermatic artery; 42, caudal vein; 43 , common iliac artery; 44 , external iliac artery; 45 , internal iliac artery; 57 , renal vein; 58 , renal artery; 61 , caudal artery. 
VEINS AND LYMPHATICS IN TRAGULLS

PLATE 1

FREDERICK TII.YLY

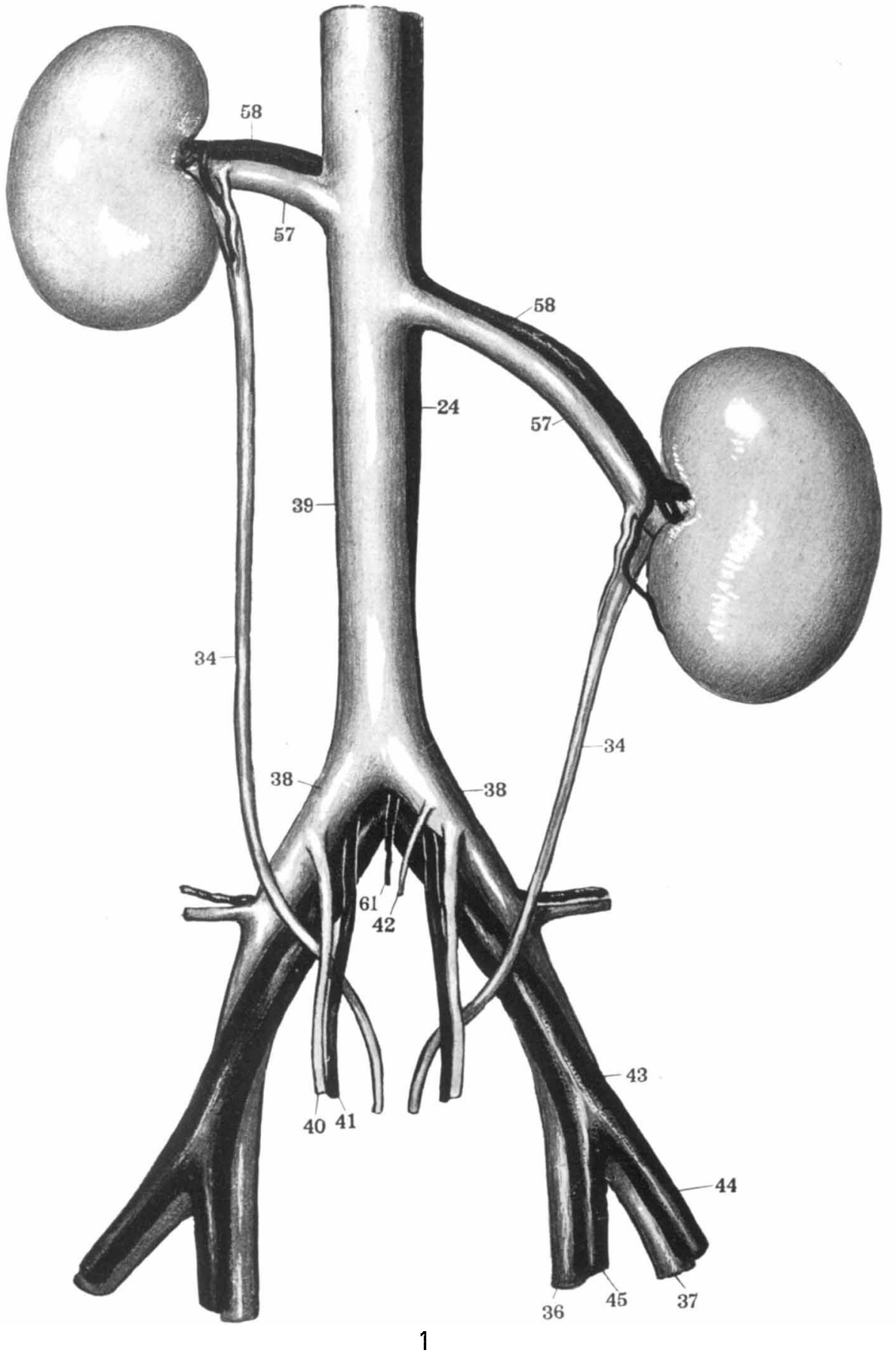

223

THE AMORICAN JOURNAL OF ANATOMY, vOL. 13 , NU. 2 


\section{PLATE 2}

\section{EXPLANATION OF FIGLKF}

2 From a reconstruction of a $5 \mathrm{~mm}$. Tragulus embryo. Collection No. 204. $\times 100$. Showing the symmetrical arrangement of the axial venous channels and the plexuses in connection with them. 1 , aortic arches; 2 , pre-curdinal vein; 3 , dorsal pre-cardinal tributaries; 4 , dorsal aorta; $\overline{5}$, post-cardinal vein; 6 , umbilical vein; 7 , umbilico-post-cardinal plexus; 8 , perimesonephroic plexus, 9 , omphalomesenteric vein; 10 , duct of Cuvier. 


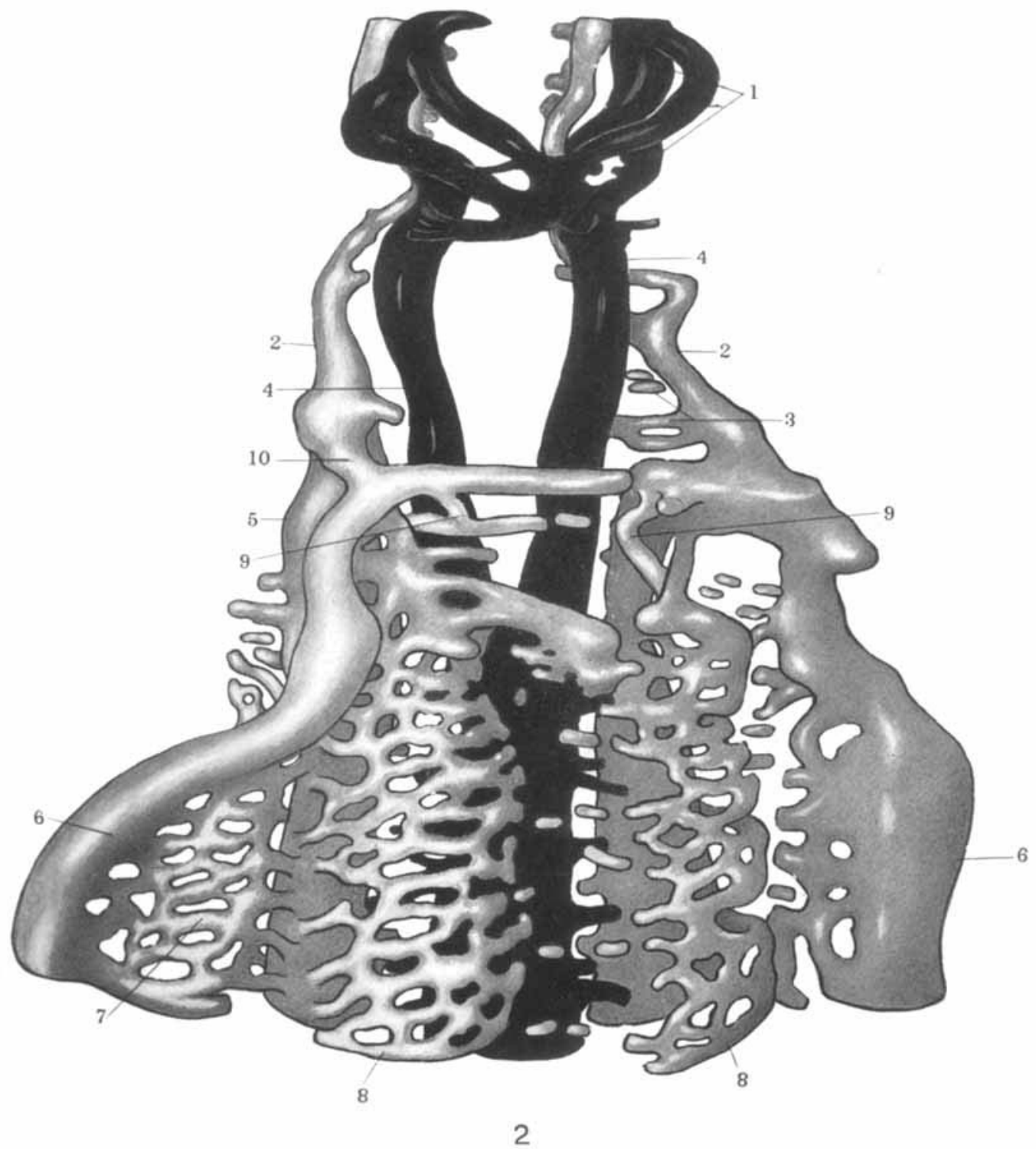




\section{PLATE 3}

\section{EXPLANATION OF FIGURFA}

3 Reconstruction of a portion of the pcrimesonephroic plexus in a $5 \mathrm{~mm}$. Tragulus embryo. Collection No. 204. $\times 200.5$, post-cardinal vein; 24, aorta; 46 , mesial portion of perimesonephroic plexus; 47 , ventral portion of perimesonephroic plexus.

4 Cross scetion showing the relations of the perimesonephroic plexus in a $5 \mathrm{~mm}$. Tragulus embryo. Collection No. 204. $\times 200.5$, post-cardinal vein; 8 , perimesonephroic plexus; 13 , Wolfian duct; 46 , mesial portion of the perimesonephroic plexus; 48 , mesonephros. 
VEINS AND LYMPHATICS IN TRAGULUS

PLATL 3

FREDERICK TILAUY

24
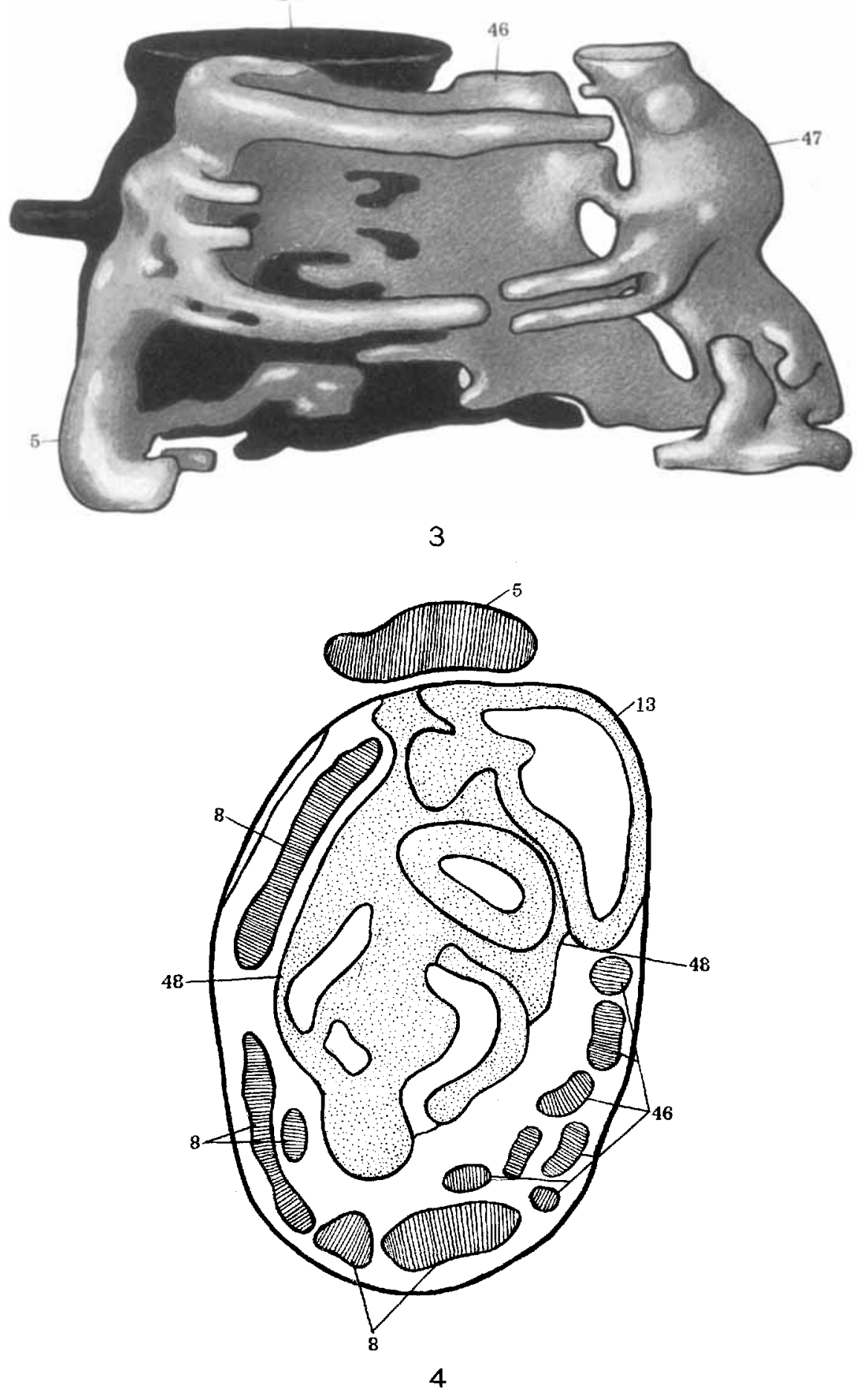


\section{PLATE 4}

\section{WXPLANATIOX OH FIGTRE}

5 Reconstruction of a $6 \mathrm{~mm}$. Tragulus embryo. Collection No. 205. $\times 100$. Showing the arrangement of the axial venous ehannels. 1, aortic arches; 2 , pre-cardinal vcin, showing its horizontal and vertical limbs; 3 , dorsal pre-cardinal tributaries; $\sigma$, post-cardinal vein; 6 , umbilical vein; 7 , umbilical-post-cardinal plexus; 9 , omphalomesenteric vein; 10, duct of Cuvier; 11 , sub-hepatic sinus; 12, sub-eardinal vein; 13 . Wolffian duct; 14 , Cloara; 24 , aorta. 


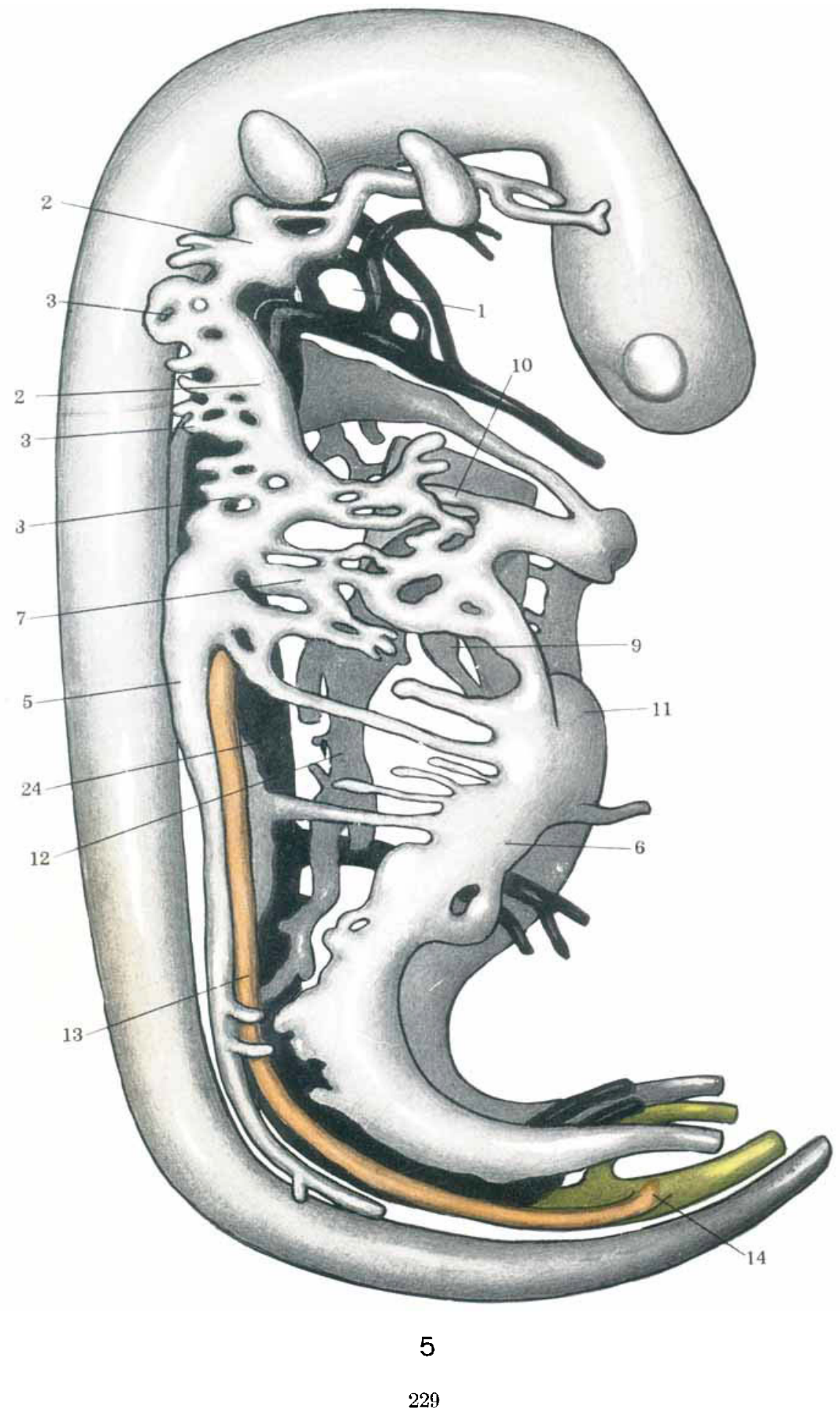




\section{PLATE 5}

\section{EXPLANATION OF FIGURE}

6 Reconstruction of a $6 \mathrm{~mm}$. Tragulus embryo. Collection No. 205. $\times 100$. Showing the region of the sub-hepatic sinus in ventral view. 5, post-cardinal vein; 6 , umbilical vein; 7 , umbilico-post-cardinal plexus; 9 , omphalo-mesenteric vein; 11 , sub-hepatic sinus; 12 , sub-cardinal vein; 13, Wolffian duct; 15 , Sinus venosus; 16 , intestine; 24 , aorta. 


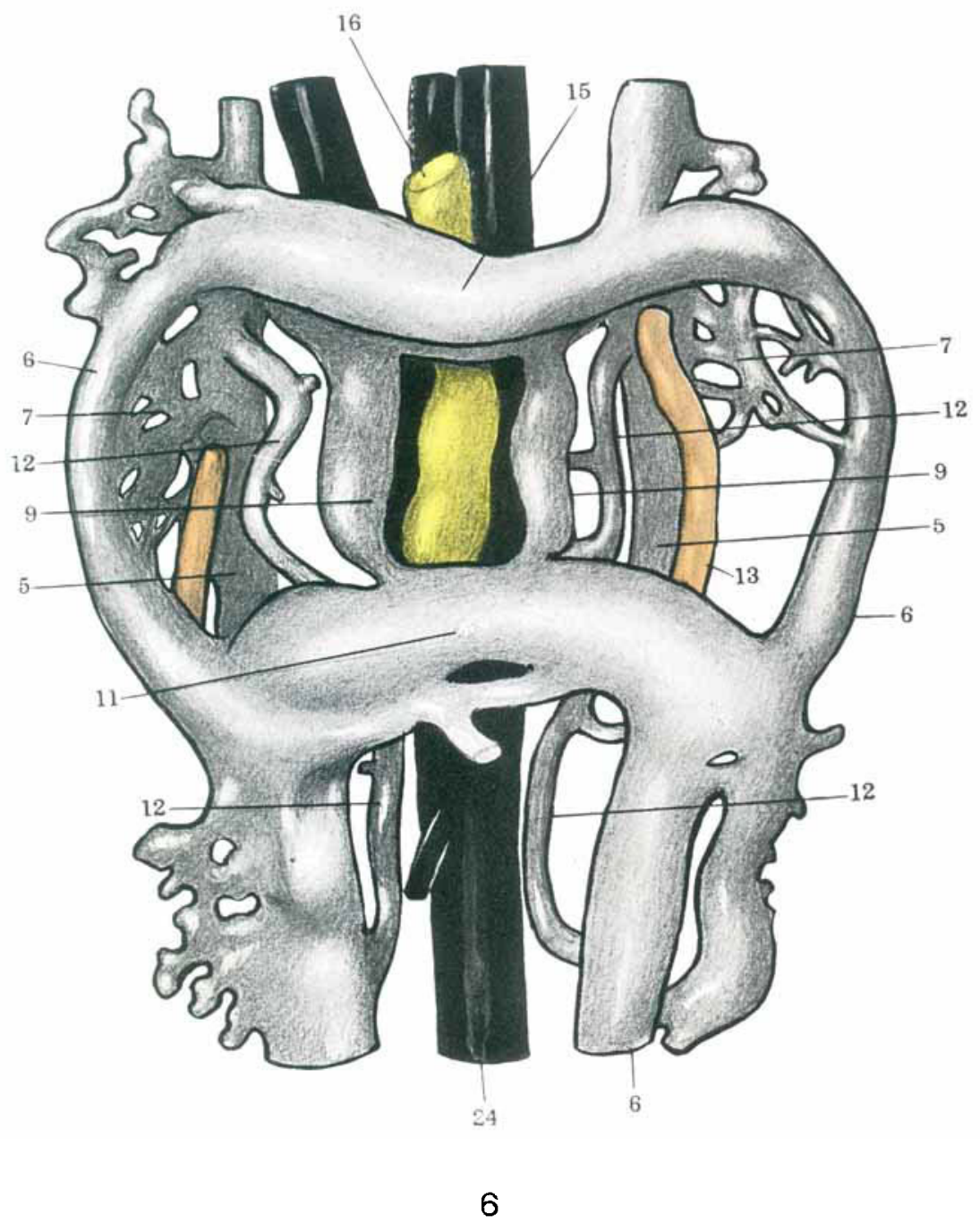


PLATE 6

\section{EXPIANATION OF FIGURE}

7 Reconstruction of a $20 \mathrm{~mm}$. Tragulus embryo. Collection No.202. $\times 100$. Showing the axial vcins and lymphatics. 6 , umbilical vein; 17 , pre-cava; 18 , hepatic portion of post-cava; 19, sub-hepatic portion of post-cava; 20 , postcardino-cardinal collateral anastomosis; 21 , cardinal collatcral vein; 22, conflucnce of iliac veins; 28 , arch of aorta; 24 , aorta; 25 , jugula lymph sac; 26 , dorso-lateral process of the lymph sac; $26 a$, dorsal descending process of the lymph sac (thoracic duct approaeh); 265 , ventral descending process of the lymph sac (bronchomediastinal approach); 28 , azygos segment of thoracie duct; 29, post-azygos segment of thoracic duct; 30 , cephalic division of pre-azygos segment of thoracic duct; 31, caudal division of pre-azygos segment of thoracic duct; 32, sympathetic nerve; 39 , vagus nerve; 34 , ureter; 35 , jugular voin; 51 , azygos vein; 62 , dorsal segmental vein; 68 , pancreas. 
VEINS ANT LYMPHATICS IN TRAGULUS

PLATE 6 FREDTRICK TILNFY

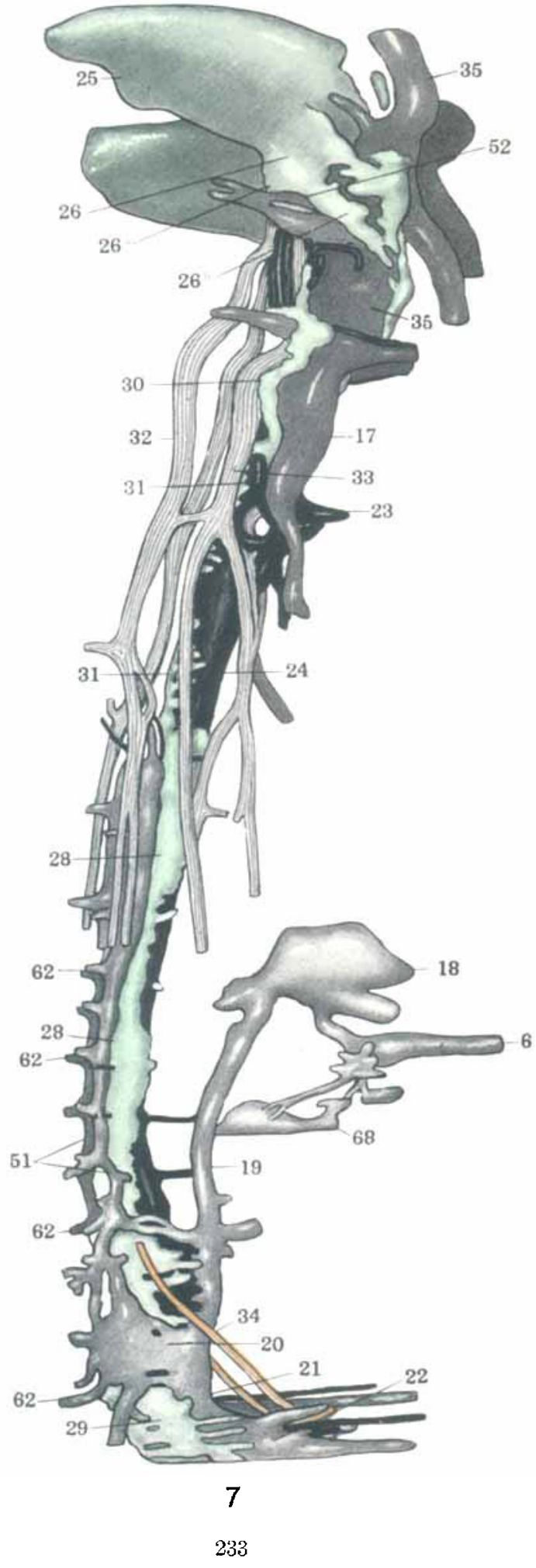




\section{PLATE 7}

\section{EXPLANATION OF FIQURE}

8 Reconstruction showing the junction of the azygos and pre-azygos segments of the thoracic duct in a $20 \mathrm{~mm}$. Tragulus embryo. Collection No. 202. $\times 100$. 24 , aorta; 28 , azygos segment of the thoracic duct; 31 , eaudal division of the preazygos segment of the thoracic duct; 50, junction of the azygos and pre-azygos segments of the thoracic duct. 
VELNS AND I.YMPHATICS IN TRAGULUS

PLATE 7 FRE DERICK TILNEY

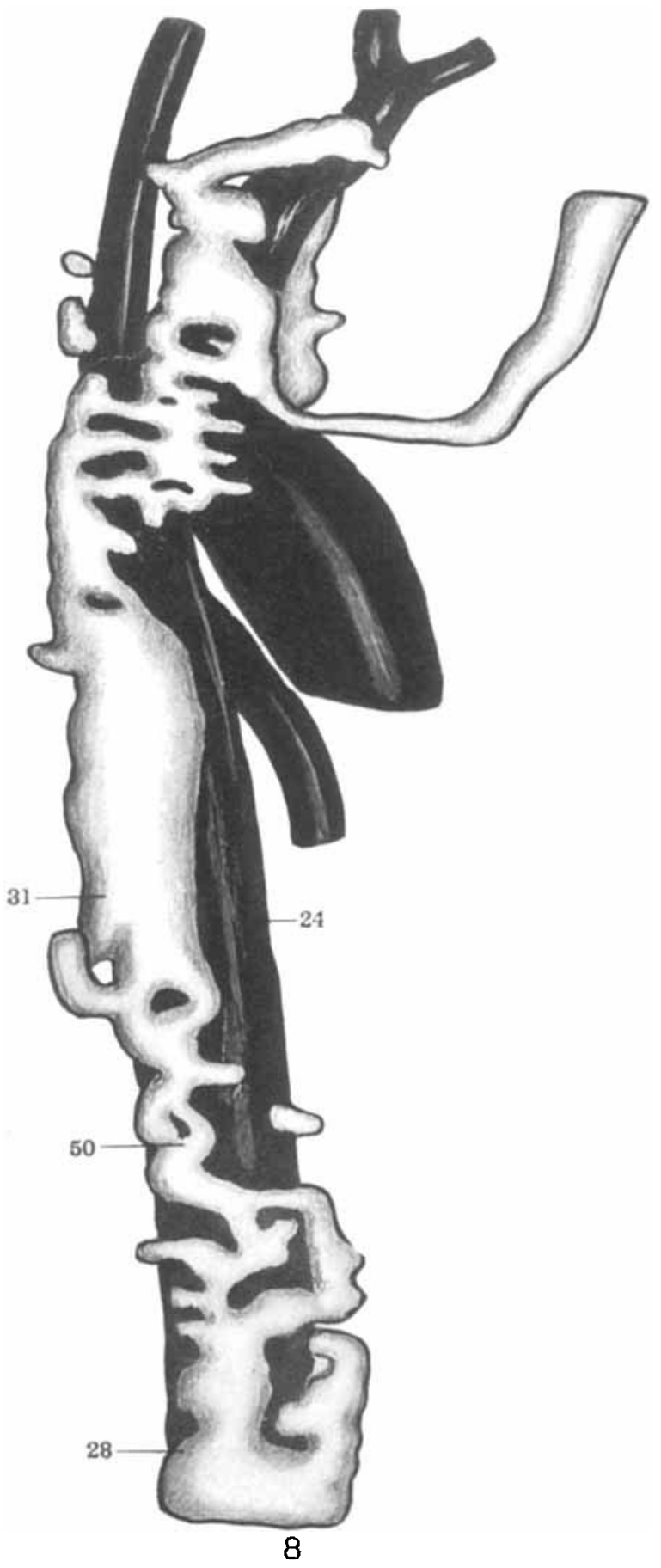




\section{PLATE: 8}

\section{FXPLANATION OF FIGURE}

9 Cross section through the azygos segment of the thoracie duct showing its resemblanee to the reptilian type of thoraeic duet. $20 \mathrm{~mm}$. Tragulus cmbryo. Collection No. 202. $\times 100$. 24, aorta; 28 , azygos segment of thoracic duct completely surrounding aorta; 51 , azygos vein. 
VIINS AND LYMPHATICS IN TRAGULCS

PLATE 8 FREDERICK TIL NUY

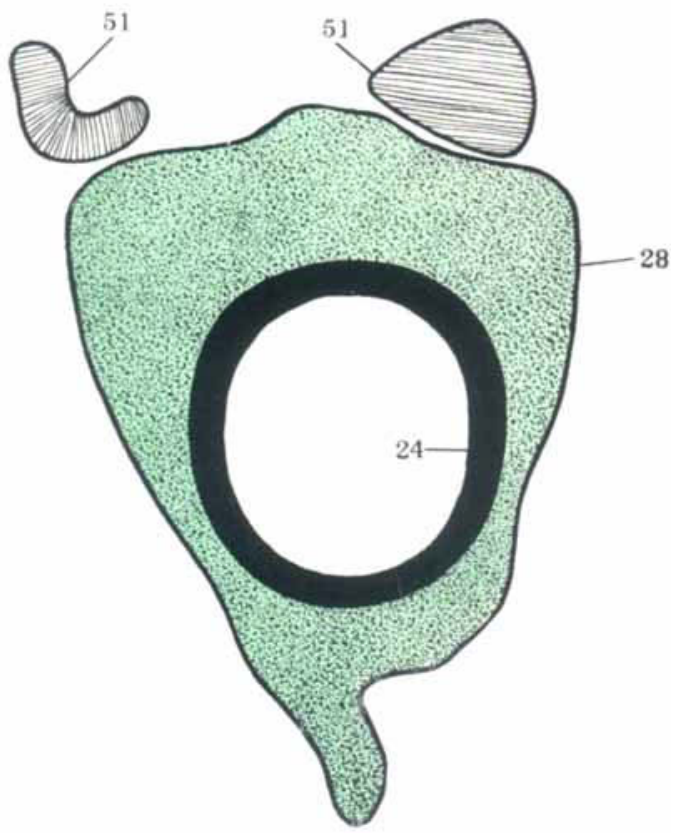

9 


\section{PLATE 9}

\section{EXPLANATION OF FIGURE}

10 Reconstruction showing the axial veins and lymphaties in a $23 \mathrm{~mm}$. Tragulus embryo. Collection No. 228. $\times 100.2$, pre-cardinal vein; 23 , arch of aorta; 25 , jugular lymph sac; 26, dorso-lateral process of the lymph sac; 28 , azygos segment of thoracic duct; 29 , post-azygos segment of thoracic duct; 31 , caudal division of the pre-azygos segment of the thoracic duct; 32, sympathetic nerve; 38 , vagus nerve; 35 , jugular vein; 51 , azygos vein; 62 , dorsal segmental vein; 65, sub-hepatic portion of post-cava. 
VEINS AND LYMPHATICS IN TRAGULUS

PLATE 9

TREDERICK TIT NEY

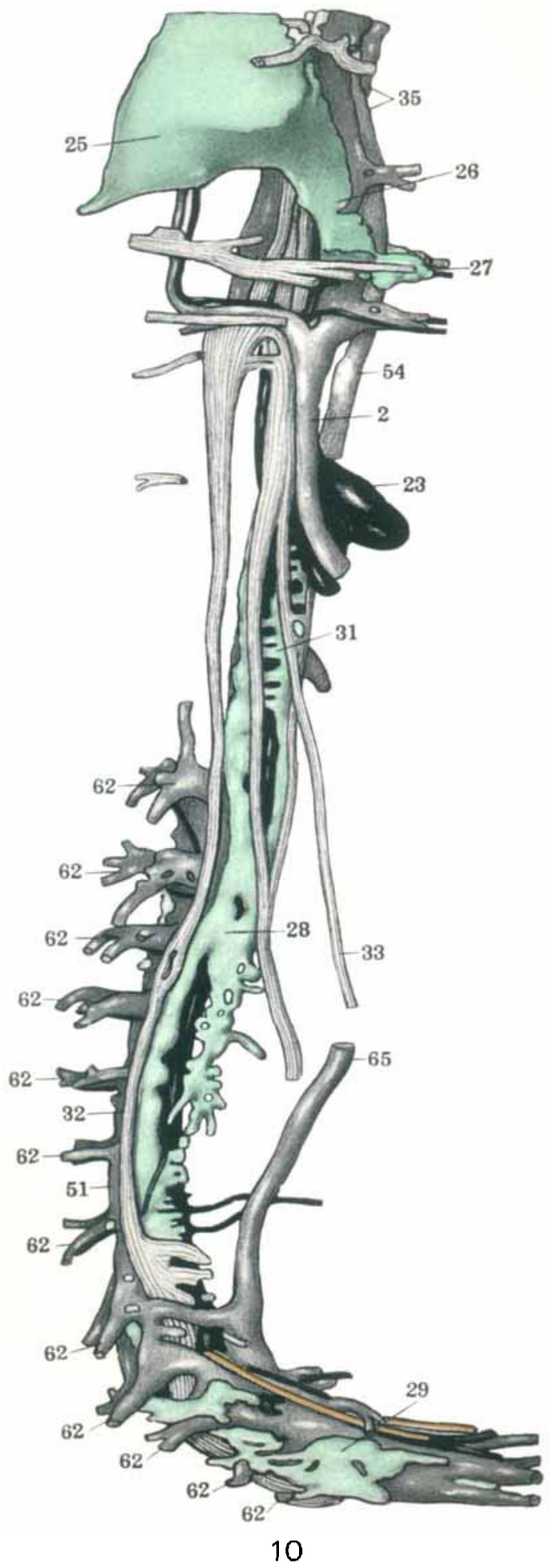

THE AMERICAN JOURNAL OF ANATOMY, VOL. 13, NO, 2 


\section{PIATE 10}

\section{EXPLANATION OF FIGURE}

$11 A, B$, and $C$. Three serial sections showing the $\cdot$ ann ${ }^{m}$ in which the left jugulo-sub-clavian tap of the lymph sac is made in a $23 \mathrm{~mm}$. Tragulus embryo. Collection No. $228 . \times 100$. $26 a$, dorsal descending process of the lymph sac (thoracic duct approach); $2 \%$, ventral descending process of the lymph sac (bronchomediastina approach); 52, jugulo-sub-clavian approach; 53, confluence of the jugular veins; 54 , thymus; 55 , thyro-cervical artery, $\tilde{c} 6$, sub-elavian vein; 65 , ventral prolongation of the jugulo-sub-clavian apprcaxh. The relations of the structure marked 52 in the three figures indicate the manner in which the secondary connection between the lymph sac and the venous system is made. 
VEINS AND LYMPHATICS IN TRAGULUS

PLATE 10 FREUERICK TILNEY

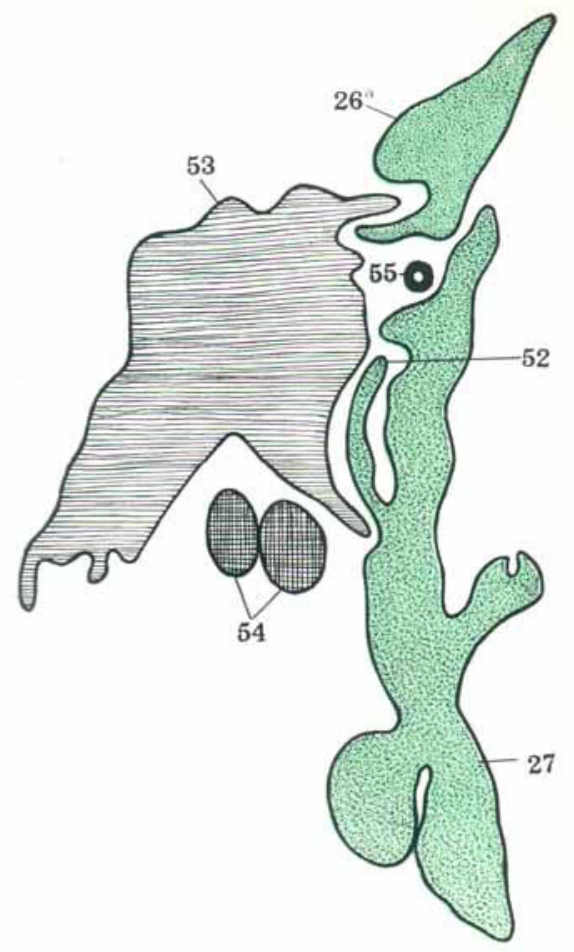

A

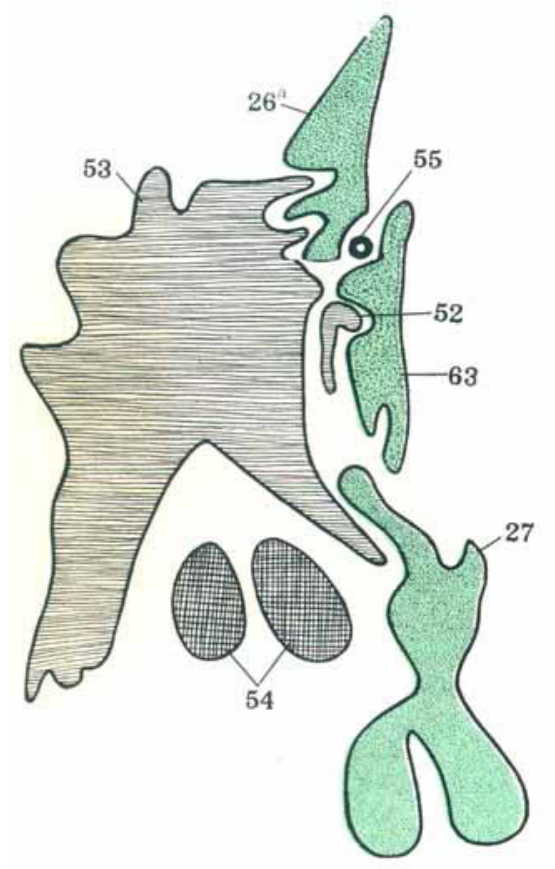

B

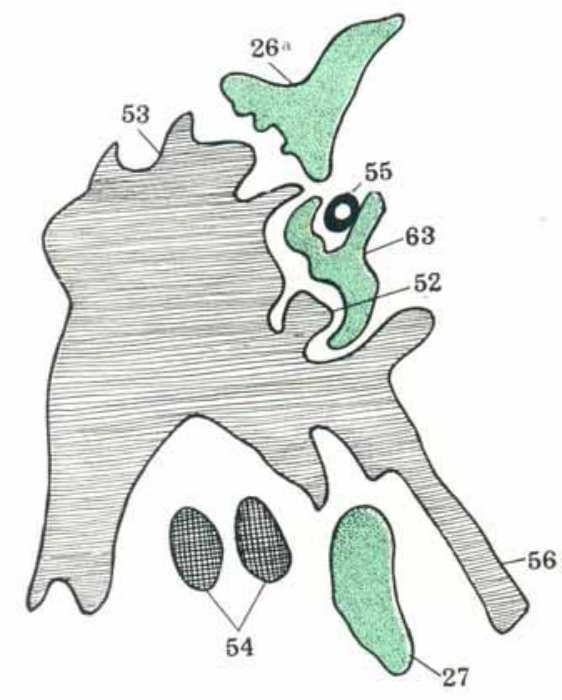




\section{PI ATF 11}

\section{EXPIANATION OF FIGIRE}

12 Reconstruction showing the junction of the azygos and pre-azygos segments of the thoracic duct in a $23 \mathrm{~mm}$. Tragulus embryo. Collection No. 228 . $\times 100$. 23, arch of aorta; 24, aorta; 28, azygos segment of the thoracic duct; 30 , cephalic division of the pre-azygos segment of the thoraric duct; 31 , caudal division of the pre-azygos segment of the thoracic duct; $30-31$, confluence of the two divisions of the pre-azygos segment of the thoracic duct; 50 , junction of the azygos and pre-azygos segments of the thoracic duet. 
VEINS AND LYMPIHATCS IN TRAGULUS

PLATE 11

FHEDERICK TLLNEY

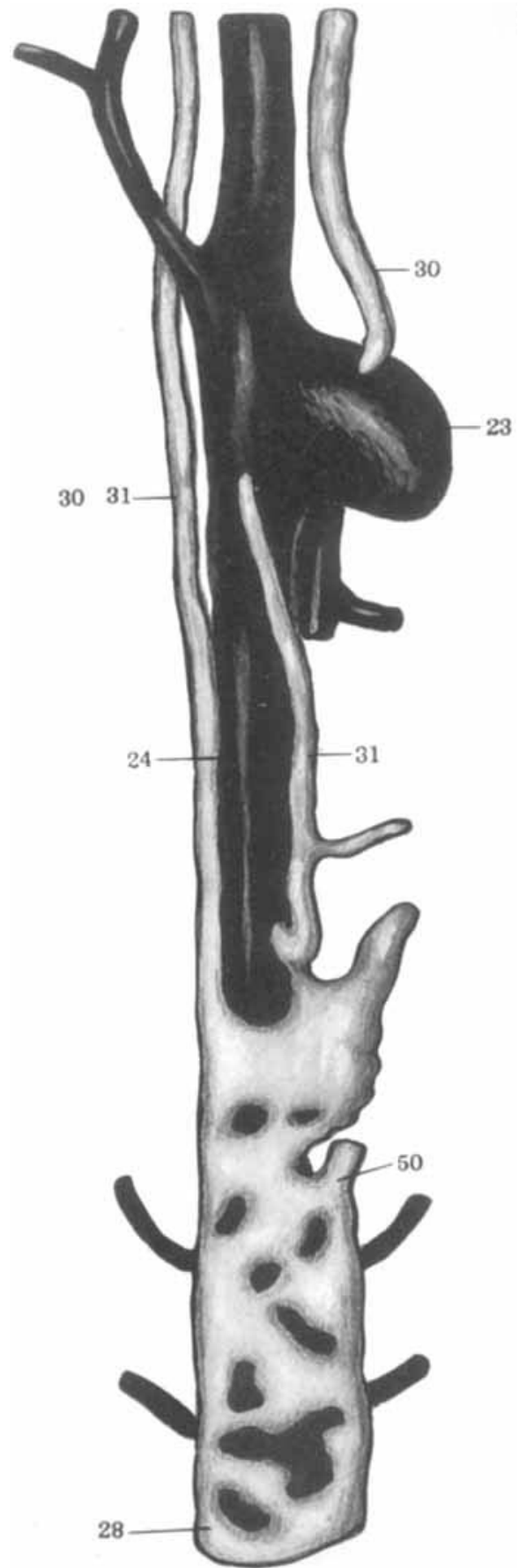

12

243 
PLATF 12

\section{EXPLANATION OF FIGURES}

$13 \mathrm{a}$ and $13 \mathrm{~b}$ Schemata giving a ventral vicw of the relations of the postcava to the aorta in a $20 \mathrm{~mm}$. and a $23 \mathrm{~mm}$. Tragulus embryo respectively, as shown by reconstructions of these stages. 21, cardinal collateral vein; 24 , aorta; 40 , sex vein; 41 , spermatic artery; 57 , renal vein; 59 , inter-renal segment of the cava; 60 , iliac bifureation of the aorta. 
VEINS AND LYMPHATICS IN TRAGULUS FRHDERICK TILNEY

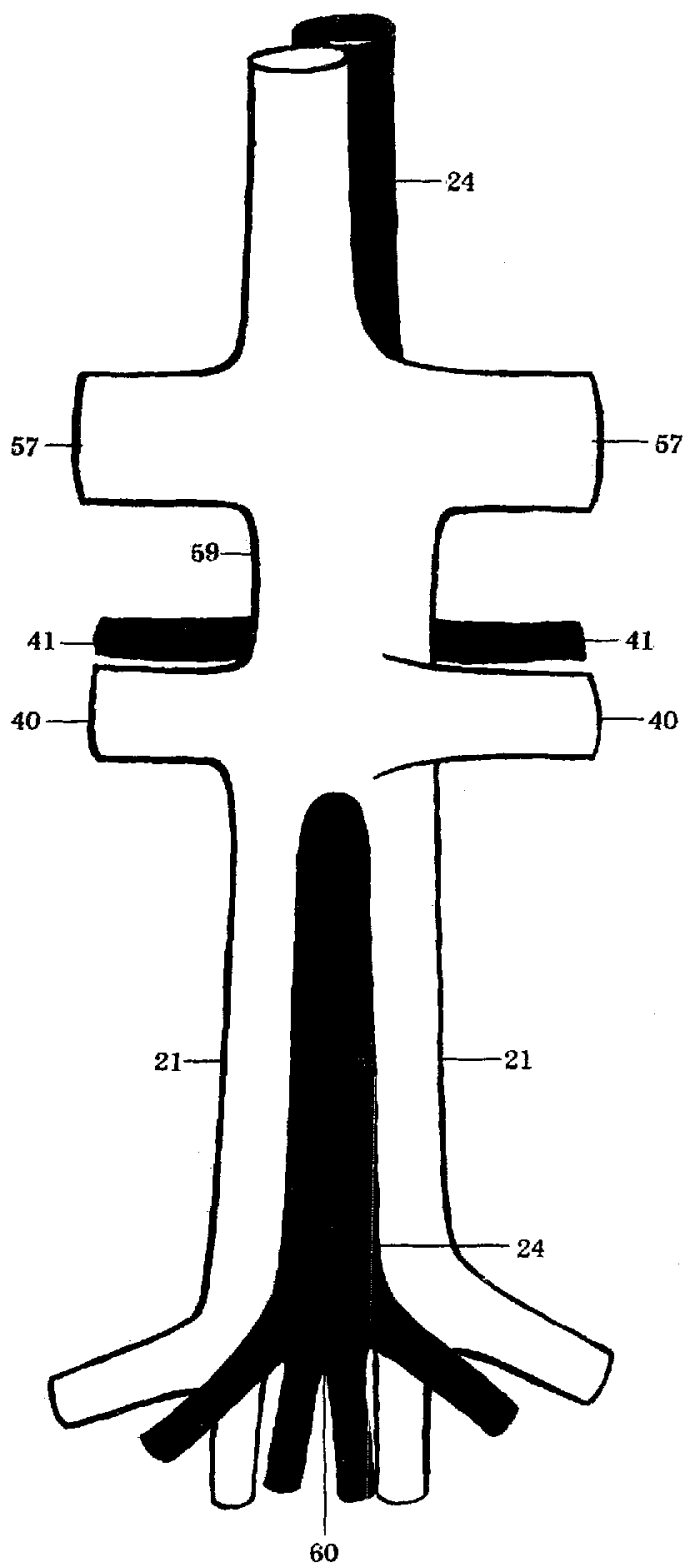

$13 \mathrm{~A}$

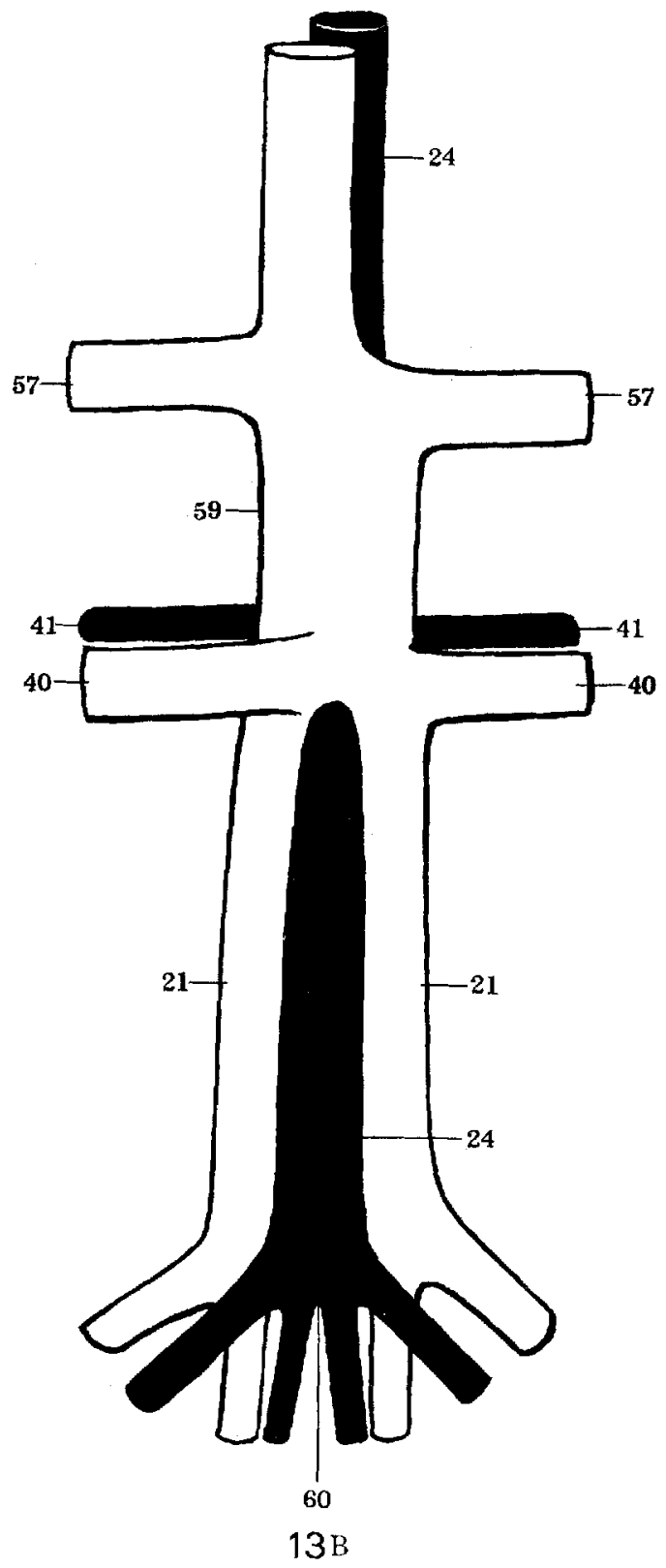




\section{PLATE 13}

\section{EXPLANATION OF FIGURF}

14 Cross section showing the anastomosis between the cardinal collateral and azygos veins in a $23 \mathrm{~mm}$. Tragulus embryo. Collection No. 228. 21, cardinal collateral vein; 24, aorta; 28 , azygos segment of the thoracie duct; 51 , azygos vein; 61 , anastonosis between curdinal collateral and azygos veins. 


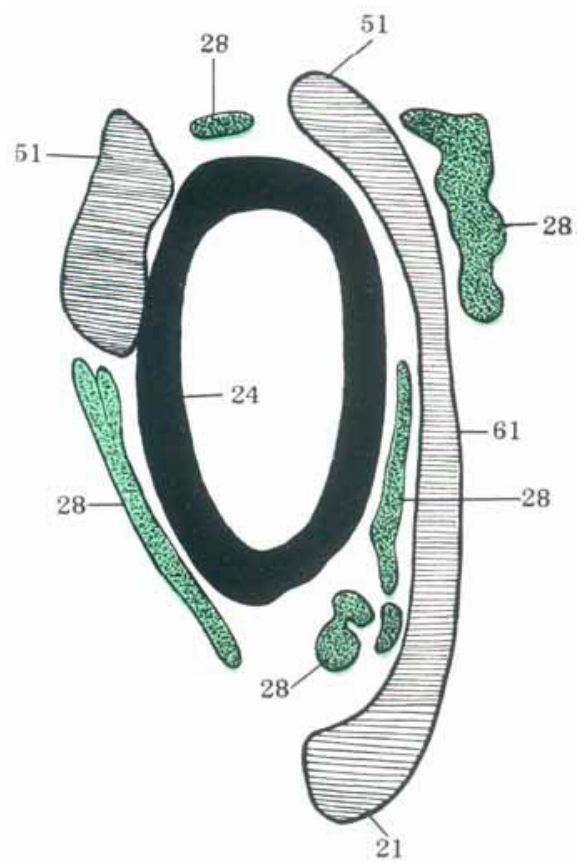

14 